\title{
Gleb Vsevolodovich Dobrovolskii Is 95 Years Old
}

DOI: $10.1134 / \mathrm{S} 1062359011030162$

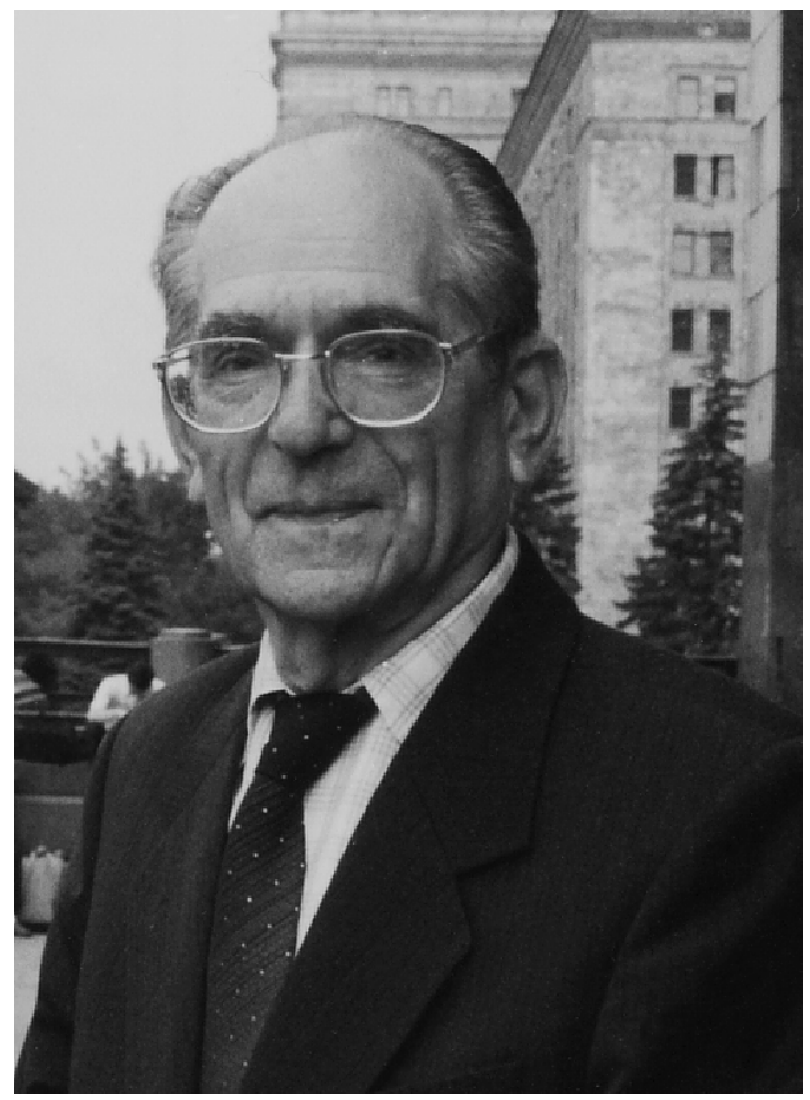

September 22, 2010, marked the 95th birthday of Gleb Vsevolodovich Dobrovolskii, doctor of biological sciences, honored professor, academician of the Russian Academy of Sciences, and director of the Institute of Ecological Soil Science at Moscow State University (MSU).

Dobrovolskii is the creator of the leading Russian scientific school "Ecologic and Genetic Soil Studies" and author of more than 500 scientific works, including 15 monographs and manuals. He was the first to develop the theoretical foundations of the genesis, classification, and rational use of alluvial soils, to reveal the ecological and geochemical regularities of soil formation in river valleys and deltas. Dobrovolskii has formulated and developed the fundamental scientific concept of the ecological and genetic soil functions in the biosphere; he is the author and editor of many soil maps of Russia and neighboring countries.

Dobrovolskii has been reading the courses of lectures on geography, systematization, and classification of soils and the history and methodology of soil science for many years. He initiated the organization of the first soil science faculty in the system of university education and organized the Institute of Ecological Soil Science at MSU.

Dobrovolskii is the chairman of the Scientific Council for soil science problems of the Russian Academy of Sciences, a member of Scientific Councils of the Russian Academy of Sciences and expert councils of the State Commission for Academic Degrees and Titles of the Soviet Union and Russian Federation, and President and honored member of the Dokuchaev Soil Science Society under the Russian Academy of Sciences. In 2002, he was elected an Honored Member of the International Union of Soil Sciences. Dobrovolskii was awarded a number of governmental prizes, as well as gold medals and prizes of the Russian Academy of Sciences.

We wish you, dear Gleb Vsevolodovich, solid health and success in developing soil science. 